NASA Technical Memorandum 83723

\title{
Lubricant Jet Flow Phenomena in Spur and Helical Gears With Modified Center Distances and/or Addendums-for Out-of-Mesh Conditions
}

Lee S. Akin

California State University at Long Beach Long Beach, California

and

Dennis P. Townsend Lewis Research Center Cleveland, Ohio

Prepared for the

Fourth International Power Transmission and Gearing Conference sponsored by the American Society of Mechanical Engineers Cambridge, Massachusetts, October 10-12, 1984 
LUBRICANT JET FLOW PHENOMENA IN SPUR ANO HELICAL

GEARS WITH MODIFIED CENTER DISTANCES AND/OR

ADDENDUMS - FOR OUT-OF-MESH CONOITIONS

\author{
Lee S. Akin \\ California State University at Long Beach \\ Long Beach, California \\ Dennis $P$. Townsend \\ National Aeronautics and Space Administration \\ Lewis Research Center \\ Cleveland, Ohio 44135
}

\title{
ABSTRACT
}

The work reported is an extension from a previous study which was ilmited to standard centers and tooth proportions only. This paper includes long and short addendums and modified center distances. The analysis develops the equations for the limit values of variables necessary to remove prior severe limitations or constraints necessary to facilitate computer analysis. A new computer program IMPOUT2 has been developed using these newly established "Limit Formulas" to prevent negative impingement on the pinion. The industrial standard nozzle orientation usually found where the offset "S = O" and inclination angle " $B=0$ " will often cause the pinion to be deprived of primary impingement which can be an important cause of incipient scoring fallure in highspeed drives.

\section{NOMENCLATURE}

${ }_{L_{p}}^{C_{p}}$

$$
\begin{aligned}
& c+\Delta a_{p}+a_{g}=\text { operating center distance (in.) } \\
& \text { impingement distance for pinion (see fig. 3) (in.) } \\
& \text { impingement distance for gear (see fig. 5) (in.) }
\end{aligned}
$$






${ }_{R}^{N} \cdot N_{g}$

$R_{a}=R_{x} \cos B$

$R_{b}$

$R_{1}$

Ror

$R_{r}=C_{r} N_{g}{ }^{\prime}$

$\left(N_{g}+N_{p}\right)$

$S$

$$
\begin{aligned}
& S_{1}=S / S_{0} \\
& S_{1}(\min ) \\
& =S(\min ) / S_{0}
\end{aligned}
$$

$s_{0}$

$a_{g r}=R_{o r}-R_{r}$

$a_{p r}=r_{\text {or }}-r_{r}$

d

$d_{p}$

$d_{p}^{p}(\max )$

$\operatorname{lnv\phi _{og}}=$
$\tan \phi_{o g}-\phi_{o g}$

$\mathrm{m}_{\mathrm{g}}$

$p_{\text {n }}$

$r$

$r_{a}=r_{x} \cos B$

$r_{b}=r \cos \phi_{t}$

$r_{o r}=r_{0}+\Delta a_{p}$

$r_{r}=C_{r} N_{p} /$

$\left(N_{p}+N_{g}\right)$

number of teeth in pinion and gear respectively

standard pitch radius of gear

perpendicular distance from gear center (in.)

base radius of gear (in.)

$\left(R_{\text {or }}^{2}-R_{s}^{2}\right)^{1 / 2}$ offset normal (in.)

$R_{0}+\Delta a_{g}$ operating outside radius of gear (in.)

running or operating pitch radius

of gear (in.)

$R_{r}+S$ radius to gear offset from gear center (in.)

gear radius to coincidence of 0.D.'s (in.)

offset of jet stream on gear 0.0. (see figs. 1 and 2)

(in.)

dimensionless offset

minimum theoretical dimensionless offset when

$d_{p}(\max )=0$ and $v_{j} \infty$ simultaneously (see

figs. 11 and 12)

offset of jet to crotch (or coincidence) of 0.0.'s (see

fig. 1) (in.)

offset of jet stream on pinion 0.0. (see fig. 4) (in.)

ofl jet velocity from nozzle exit (in./sec)

jet velocity when $d_{p}=0$ for given $\omega_{p}($ in./sec)

operating gear addendum (in.)

operating pinion addendum (in.)

depth of impingement on gear (in.)

depth of impingement on pinion (in.)

maximum theoretical depth on pinion $v_{g} \infty$

involute function of $\phi_{\text {og }}$ (typical) (rad.)

gear reduction ratio

normal diametral pitch

standard pitch radius of pinion

perpendicular distance for pinion center (in.)

base radius of pinion (in.)

operating outside radius of pinion (in.)

running or operating pitch radius of pinion (in.) 




offset radius from pinion center (in.)

pinton radius to coincidence of 0.D.'s (in.)

generalized time of jet flight and gear rotation (sec)

total time of flight to jet impingement ( $\mathrm{sec}$ )

total time of rotation (sec)

arbitrary offset distance from $S$ (see fig. 2) (in.)

arbitrary incilination angle of jet stream (rad.)

normalized positive inclination angle

normaltzed negative inclination angle

maximum inciination angle permitted

minimum inclination angle permitted

inclination angle when jet passes through pitch point

(rad.)

inclination angle when jet passes through crotch of

O.D.'s and pitch point $\left(S=S_{0}\right)$ (rad.)

dimensionless impingement depth, pinion or gear

gear addendum modification (in.)

pinion addendum modification (in.)

tooth addendum modification for $\Delta a_{g}$

tooth addendum modification for $\Delta a_{p}$

differential jet pressure at nozzle exit (psi)

angular velocity of pinton ( $\mathrm{rad} / \mathrm{sec}$ )

normal pressure angle (rad.)

pressure angle at 0.0. of gear (rad.)

pressure angle at lowest impingement point on pinion

( rad.)

pressure angle at 0.D. of pinton (rad.)

tangential standard pressure angle (rad.)

tangential operating pressure angle (rad.)

helix angle (deg.)

initial position of gear tooth at beginning of pinion impingement cycle $(t=0)(\mathrm{rad}$. 
$\theta_{g 2}$
$\theta_{g 3}$
$\theta_{p 1}$
$\theta_{p 2}$
$\theta_{p 3}$
$\theta_{p 4}$

initial position of gear tooth at beginning of gear impingement cycle (rad.)

final position of gear at max. impingement depth $\left(t_{f}=t_{w}\right)(\mathrm{rad}$.

initial angular position of pinion tooth at beginning of pinion impingement cycle $(t=0)$ (rad.)

final position of pinion tooth at maximum impingement $\operatorname{depth}\left(t_{s}=t_{w}\right)(\operatorname{rad}$.

final position of pinion tooth when just missed by jet stream $(t=0)($ rad. $)$

initial position of pinion tooth at beginning of gear impingement cycle $(t=0)(\mathrm{rad}$.

\section{INTROOUCTION}

In the gearing industry, gears are lubricated and cooled by varlous methods. At low to moderate speeds and loads, gears may be partly submerged in the lubricant which provides lubrication and cooling by splash lubrication (ref. 1). With splash lubrication, power loss increases considerably with speed as shown in Ref. 1 . This is partially because of churning losses. In Ref. 2 it is shown that gear scoring and surface pitting can occur when the gear teeth are not adequately lubricated and cooled. The results of Ref. 3 for spur gear oll jet lubrication show that as the gear pitch line velocity increases at a constant into-mesh iubrication condition, the limiting tooth load that will cause gear scoring is drastically reduced. This is primarily because the method of lubrication does not provide adequate cooling at the increased pitch line velocity. In a study of high speed heavy duty gears (ref. 4) the authors showed that the o1l jet location and amount of 011 flow to the gears varies nearly linearly with gear pitch line velocity and also with tooth load. In Ref. 5 the authors showed that with radial jet lubrication the gear tooth temperature at various speed and loads can be considerably reduced by increasing the lubricant jet pressure and flow rate to obtain better cooling. It was shown in Refs. 5 and 6 that the ofl jet lubrication is the most effective method when the jet is directed in the radial direction with adequate pressure and flow. Many gears are lubricated by directing the 011 jet at the engaging side of the mesh (into mesh lubrication) or at the disengaging sides of the gear mesh (out of mesh lubrication). In Refs. 7 and 8 , the authors analyzed o1l jet lubrication when the o1l jet is directed at the 
engaging side of the gear mesh. In Refs. 7 and 8 it was shown that there is an optimum oll jet velocity and 011 jet location to obtain the best lubrication and cooling for into-mesh lubrication.

In Ref. 9 the oll jet lubrication for out of mesh lubrication was analyzed and the o11 jet impingement depth was determined for standard gearing dimensions. Also in Ref. 9 the oll jet location an direction were limited to a no offset condition (directed at the pitch point only) and in a direction normal to the line of center. This method will give good results for standard gear dimensions with gear ratios close to unity. However, when nonstandard dimension, spread center distance, etc. and large gear ration are used the oll jet direction and location should be changed to provide the optimum oll jet impingement depth and maximum cooling condition.

The objective of the work reported herein is to analyze the out of mesh jet lubrication with most of the simplifying constraints used in reference 9 removed. Since most high performance gears require addendum modifications and in addition sometimes spread centers, the analysis presented herein set out to include these and other related conditions. One practical constraint is added: a nozzle orientation that allows a pinion or gear to be missed provides no primary cooling to the missed member. Such solutions are not permitted in this analysis since they are not of practical value and can mislead an inexperienced gear design engineer.

\section{BRIEF DESCRIPTION OF THE IMPINGEMENT CYCLE}

The beginning of the pinion impingement cycle is about to start as the leading edge of the top land of the gear is passed as shown in Fig. 1. Gear tooth rotation continues toward the jet stream unt $\{1$ the jet reaches the tralling edge of the gear tooth as shown in Fig. 2. At this position the time $t$ is set at zero $(t=0)$ and the geometrical position of the gear $\theta_{g}$ is calculated. Also the initial position of the pinion $\theta_{p l}$ is calculated at $(t=0)$. Then the geometry of the lowest impingement point on the pinion is established by setting the time of flight of the jet stream head equal to the time of rotation on the pinion from $(t=0)$ until impingement on the pinion takes place at $\theta_{p 2}$ as shown in Fig. $3,\left(\theta . t_{f}=t_{w}\right)$. Figure 4 shows the initial position of the jet head ( $\theta t=0$ ) when the impingement flow toward the lowest impingement point on the gear is initiated. Here the initial position of the pinion is $\theta_{p 4}$ and $\theta_{g 2}$ for the gear. Again the times of 
flight and rotation are equated $\left(t_{f}=t_{w}\right)$. Impingement at the lowest point on the gear $\left(L_{g}\right)$ is shown in $f i g .5$. The gear position is $\theta_{g 3}$ at this lowest point of impingement.'

Thus the depth of primary impingement on the gear is $d_{g}$ as shown in the figure. When the jet velocity $v_{g}$ is reduced below $v_{j}(\min )$ the pinion is missed and the impingement depth on the gear is not increased as expected but reduced.

\section{MODEL CONTROLS AND RESTRAINTS}

Development of the mathematical model used in Ref. 1 was restricted to spur gears and the nozzle position was restricted to the arbitrary offset distance $S=0$ and arbitrary inclination angle $B=0$ orlentation. The geometric definition of $S$ and $B$ are described below and shown in Fig. 1 . The above restrictions have been removed in this mathematical development. Also the origin for the jet stream trajectory is defined as the position where the jet crosses the gear outside diameter (0.D.) as shown in Fig. 1 at A, B, and C. Position A shows the general case where $0<S<S_{0}$ and $B$ is a special case where $S=S_{0}$ and $C$ is the classic case where $S=0$ pointing at the pitch point and perpendicular to the line of centers.

In this paper the value of the arbitrary offset $S$ where the jet line crosses the gear I.D. Is restricted to $S(\min ) \leq S \leq S_{0}$ where

$$
s_{0}=\frac{\left(a_{g r} m_{g}-a_{p r}\right)}{m_{g}+1}+\frac{a_{g r}^{2}-a_{p r}^{2}}{2 r_{r}\left(m_{g}+1\right)}
$$

as shown in Fig. 1 (see Nomenclature for varlable definitions not described in text). Thus the operating (or running) offset $S_{0}$ to the crotch or common intersection of the outside diameters is the maximum value allowed for the offset $S$ to remain within the geometric definitions described in this paper. Further when the addendum modification $\Delta a_{p r}$ and $\Delta a_{g r}$ are unequal and extreme enough to cause $S_{0}$ to be negative then $S_{0} \leq S \leq 0$. Also when $\Delta a_{p}=\Delta a_{g}=\Delta a=0$ with standard centers, $S_{0}$ reduces to

$$
S_{0}(S t d)=\left(1 /\left(P_{n} \cos \Psi\right)\right)\left(\left(N_{g} / N_{p}\right)-1\right) /\left(\left(N_{g} / N_{p}\right)+1\right)=a\left(m_{g}-1\right) /\left(m_{g}+1\right)
$$


Also the inclination angle $B$ is confined to point at the line of centers between the confines of the outside diameters of the pinion and gear respectIvely as shown in Fig. 1.

The inclination angle $B$ is considered positive when slanted from right to left through the point of origin $A, B$, or $C$ as shown in Fig. 1. At $B=0$ the jet is pointed perpendicular to the line of centers, and when $B$ is negative it is slanted from left to right through the point of origin on the 0.D. of the gear, not shown in Fig. 1. It is not usually considered wise to use negative $B$ angles with near standard proportion gears lest we starve the gear of adequate coolant.

The mathematical definition of the arbitrary inclination angle $B$ is:

$$
B=\tan ^{-1}\left(x / R_{1}\right)
$$

where:

$$
\begin{aligned}
& R_{1}=\left(R_{\text {or }}^{2}-R_{s}^{2}\right)^{1 / 2} \text { and } \\
& x=\text { an arbitrary offset distance from "S" position to where the jet } \\
& \text { stream crosses the common line of centers. } \\
& R_{\text {or }}=R_{0}+\Delta a_{g}=\text { Operating outside radius } \\
& R_{0}=N_{g} /\left(2 P_{n} \cos \psi\right)+1 / P_{n}=\text { std. 0.D., gear } \\
& R_{S}=R_{r}+S=\text { Radius to offset from gear center } \\
& R_{r}=C_{r} N_{g} /\left(N_{g}+N_{p}\right)=\text { Operating pitch radius, gear } \\
& \Delta a_{g}=\Delta N_{p} /\left(2 p_{n} \cos \psi\right)=\text { gear addendum modification }
\end{aligned}
$$

When $B$ is given then,

$$
x=R_{1} \tan B \text {, where } B \text { is arbitrary }
$$

Thus to remain within the confines established for $B, B_{\max }$, and $B_{\min }$ are defined as:

$$
\begin{gathered}
B_{\max }=\tan ^{-1}\left[\left(S+a_{p r}\right) / R_{f}\right] \text { and } \\
B_{\min }=\tan ^{-1}\left[\left(S-a_{g r}\right) / R_{f}\right]
\end{gathered}
$$


Also, for any given offset "S" the angle $B_{p}$ to the pitch point is (used as a normalizer);

$$
B_{p}=\tan ^{-1}\left(S / R_{1}\right)
$$

and further if $S=S_{0}$ then the angle to the pitch point is

$$
B_{p p}=\tan ^{-1}\left(S_{0} / R_{1}\right)
$$

since $B$ can be arbitrartly selected, it is necessary to provide the user with a normalized (dimensionless) input value for $\beta$ that won't be out of bounds of the solvable geometry. This is done here using the $B_{1}$ input parameter where $-1 \leq B_{1} \leq 1$ and is defined as; when $B_{1}$ is positive $(+)$ :

$$
B_{1}=\frac{B-B_{p}}{B_{\max }-B_{p}},+B=B_{1}\left(B_{\max }-B_{p}\right)+B_{p}
$$

and when $B_{1}$ is negative $(-)$ :

$$
B_{1}=\frac{B-B_{p}}{B_{p}-B_{m i n}}+B=B_{p}-B_{1}\left(B_{m i n}-B_{p}\right)
$$

so that when;

$$
\begin{aligned}
& B_{1}=0: B=B_{p} \text { (pointing at pitch point) } \\
& B_{1}=1: B=B_{\max } \text { (pointing at 0.D. pin.) } \\
& B_{1}=-1: B=B_{\min } \text { (pointing at 0.D. gr.) }
\end{aligned}
$$

Further if the user desires to know the value of $B_{1}$ that will make $\beta=0$, he calculates $B_{10}$ from:

$B_{10}=\frac{B_{p}}{B_{\min }-B_{p}}$ if $B_{10}$ is negative as is usual

Similarly, when $S$ is normalized we get:

$$
\mathrm{S}_{1}=\mathrm{S} / \mathrm{S}_{0}
$$

where the value of $S_{1}$ is confined to $S_{1(\text { min })} \leq S_{1} \leq 1$. 
Thus the use of the computer program IMPOUT2 can be entered using $S_{i}$ and $B_{1}$ without knowing $S$ or $B$ with some relative feel for where the jet nozzle is pointing.

A further constraint of paramount importance is $S_{1(m i n)}$ so defined, given $B_{1}$ or $B$ and $\Delta_{p}$ and $\Delta a_{g}$, so that $d_{p(\max )}=0$ thus making the pinion 0.0. barely reachable when the jet velocity $v_{j}$ approaches infinity. This further confines $S_{1}$ so that $S_{1(\min )}<S_{1} \leq 1$ to maintain impingement at least on the top land of the pinton, where $S(m i n)$ is found by iterating:

$$
\operatorname{abs}\left[r_{o r}^{2}-r_{a}^{2}+L_{p}(\min )^{2}\right] \leq 10^{-3}
$$

as a function of $S(m i n)$ with given $B$ and $\Delta a_{p, g}$ until the inequality is satisfied when the above restraints on $S_{1}, B_{1}, \Delta a_{p}$, and $\Delta a_{g}$ are given, the user of the program IMPOUT2 is assured of impingement on the pinion. $d_{p}(\max )$ is defined later in this paper.

Once $S(m i n)$ is found from Eq. (7), $S_{i(m i n)}$ can be calculated from:

$$
S_{1(\min )}=S(\min ) / S_{0}
$$

DEVELOPMENT OF THE GEOMETRIC MODEL FOR THE PINION

The problem to be solved here depends on what is given. If the jet velocity is given then we solve explicitiy for the impingement depth $d_{p}$ so that subsequently this depth can be used to determine the cooling effect on the pinion and gear respectively. On the other hand, if the desired depth of impingement is given, and $d_{p}<d_{p}(\max )$, then the desired jet velocity "V, can be calculated explicitly from the equation:

$$
v_{j p}=\left(\left(\left(R_{o r}{ }^{2}-R_{s}{ }^{2}\right)^{1 / 2} \sec \beta-\rho_{x} \sin \beta-L_{p}\right) \omega_{p}\right) /\left(\theta_{p 2}-\theta_{p 1}\right)
$$

where 







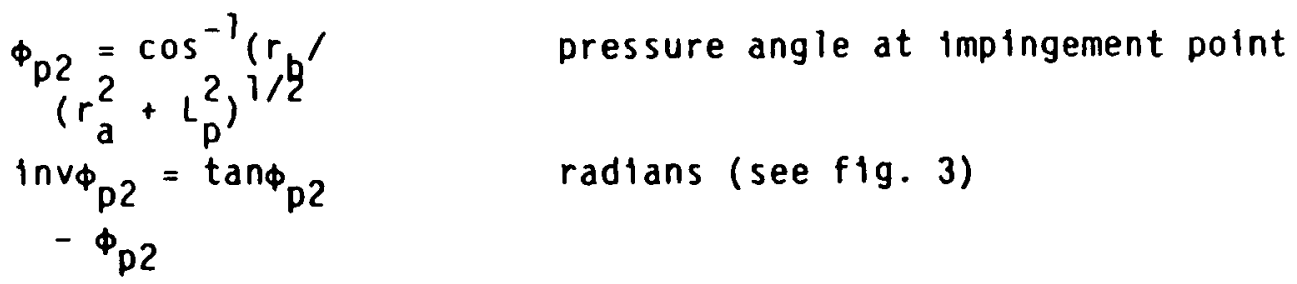

As will be seen by reviewing the input parameters, a substantial amount of calculation is required before Eq. (7) for $v_{j p}$ can be solved. Thus a computer program is required to do the job reliably, such as the program IMPOUT2 as mentioned above.

Generally solving for the required velocity to obtain a desired depth "d $p$ " on out-of-mesh cooling would be unusual mainly because of the limit. imposed by "d $d_{p}(\max )$ " which is the limiting depth of impingement when $v_{f} \rightarrow \infty$ so that $0<d_{p}<d_{p}(\max ) . d_{p}(\max )$ is calculated from:

$$
d_{p}(\max )=r_{o r}-\left(r_{a}^{2}+L_{p}(\min )^{2}\right)^{1 / 2}
$$

where:

$$
L_{p}(\min )=r_{a} \tan \left(\theta_{p 1}-i n v \phi_{p 2}\right)
$$

Note that $\phi_{p 2}=f_{n}\left(L_{p}\right)$ and $L_{p}=f_{n}(S+B)$ as $V_{j} \rightarrow \infty$

In real geared systems the jet velocity "V the system lubricant pressure so that we solve for $d_{p}$ within the range $0<d_{p}<d_{p}(\max )$ which is usually quite narrow. It is necessary when " $v_{g} "$ is given to solve for $d_{p}$ implicitly using an iterative technique. This can be accomplished by solving for the impingement distance $L_{p}$ (see fig. 3) implicitly using the equation:

$$
L_{p}=\frac{\left(R_{o r}^{2}-R_{s}^{2}\right)^{1 / 2}}{\cos B}-\frac{v_{j}\left(\theta_{p 2}-\theta_{p 1}\right)}{\omega_{p}}-r_{x} \sin B
$$

with $v_{j}$ given and noting that $\theta_{p 2}=f_{n}\left(L_{p}\right)$.

Then the depth of impingement on the pinion is: 


$$
d_{p}=r_{o r}-\left(r_{a}^{2}+L_{p}^{2}\right)^{1 / 2}
$$

where: $0<d_{p}<d_{p}(\max )$ and a negative $d_{p}$ means that the jet missed the pinton.

Missing the pinion (or neg. $d_{p}$ ) can be avoided by proper placement of the nozzle offset " $S$ " where $S(m 1 n)<S<S_{0}$ as established above and/or $v_{j}(\min )<v_{j}<\infty$ where; (see fig. 6).

$$
v_{j}(\min )_{p}=\frac{\left(\left(R_{o r}^{2}-R_{s}^{2}\right)^{1 / 2}-\left(r_{o r}^{2}-r_{a}^{2}\right)^{1 / 2}-r_{x} \sin B\right) \omega_{p}}{\left(\theta_{p 3}-\theta_{p 1}\right)}
$$

where

$$
\begin{gathered}
\theta_{p 3}=\cos ^{-1}\left(r_{a} / r_{o r}\right)+i n v_{o p} \text { (radians) } \\
\theta_{o p}=\cos ^{-1}\left(r_{b} / r_{o r}\right) \text { and } \\
\text { inv } \phi_{o p}=\tan \phi_{o p}-\phi_{o p} \text { (radians) }
\end{gathered}
$$

Equation 13 provides the minimum velocity to reach the top land of the pinion for the selected offset $S$ when $S(m i n)<S$ and $d_{p}=0$, assuming that $S_{0}$ is positive.

\section{DEVELOPMENT OF THE GEOMETRIC MODEL FOR THE GEAR}

In the case of the gear meshing with the pinion, the jet velocity of the gear is common with that for the pinion; so that even if the velocity $v_{\text {jp }}$ is found explicitiy to provide a desired or specified depth of impingement on the pinion "d ", the jet velocity for the gear is always provided by $v_{j p}=v_{g p}=v_{j}$ so that the impingement depth for the gear is always found for the implicit solution for $L_{p}$ from the equation:

$$
L_{g}=\frac{\left(r_{o r}^{2}-r_{s p}^{2}\right)^{1 / 2}}{\cos B}+r_{x} \sin \beta-\frac{v_{j}\left(\theta_{g 3}-\theta_{g 2}\right)}{\omega_{g}}
$$


where we note that

$$
\begin{aligned}
& \theta_{g 3}=f_{n}\left(L_{p}\right)(\text { see fig. 5) } \\
& r_{s p}=r_{r}-S_{p}=\text { offset radius from pinion center (See fig. 4) } \\
& S_{p}=\left(\left(r_{\text {or }}^{2}-r_{x}^{2} \cos ^{2} \beta\right)^{1 / 2}+r_{x} \cos B\right) \sin B-(x-S) \text { (see fig. 4) } \\
& R_{x}=R_{r}+S-x \\
& \theta_{g 2}=\theta_{p 4} / m_{g}+\operatorname{lnv} \phi_{t r}+\beta(\text { see fig. 4) } \\
& \theta_{g 3}=\tan ^{-1}\left(L_{g} / R_{a}\right)+\operatorname{lnv} \phi_{g 3} \text { (see fig. 5) } \\
& \left.\theta_{p 4}=\cos ^{-1}\left(r_{s p} / r_{o r}\right)-\operatorname{lnv} \phi_{o r}+\operatorname{lnv} \phi_{t r}\right)(\text { see f1g. 4) } \\
& R=R_{x} \cos B \text { (see fig. 5) } \\
& \phi_{g 3}=\cos ^{-1}\left(R_{b} / R_{a}^{2}+L_{g}^{2}\right)^{1 / 2} \text { (see fig. 5) } \\
& \text { inv } \Phi_{g 3}=\tan \Phi_{g 3}-\Phi_{g 3} \text { (radians) (see fig. 5) } \\
& \phi_{o r}=\cos ^{-1}\left(r_{b} / r_{o r}\right) \\
& \text { inv } \phi_{o r}=\tan \phi_{o r}-\phi_{o r} \text { (radians) } \\
& R_{b}=R \cos \phi_{t} \text { (see figs. } 3 \text { and } 5 \text { ) }
\end{aligned}
$$

Then the impingement depth on the gear is calculated from:

$$
d_{g}=R_{\text {or }}-\left(R_{a}^{2}+L_{g}^{2}\right)^{1 / 2}
$$

\section{COMPUTERIZED PARAMETRIC STUDY}

A rather intricate computer program has been developed which should be useful to the design engineer as well as the researcher performing parametric studies. This program "IMPOUT 2 " was used in the study for this section of the paper. 
The out-of-mesh nozzle orientation imposes severe impingement depth problems especially when the gear ratio is larger than one-to-one. This is demonstrated in Fig. 7 where it can be seen that when the gear ratio " $m_{g}$ " is equal to one $(1.0)$ the depth of jet 011 impingement is equal on pinton and gear for a perpendicular jet pointed at the pitch point. However, when $m_{g}$ is larger than unity, the impingement depth on the pinion is very dependent on the offset "S". This is shown in Fig. 7 using the dimensionless offset $S_{1}$. As can be seen when $S_{1}=1.0$, the position at the intersection of the pinion and gear 0.0.'s the jet is pointed at the pitch point $B_{1}=0$. Both pinion and gear have near equal impingement depth. But as the offset $S_{1}$ is lowered or the gear ratio is increased, the impingement on the pinion rapidly disappears. In the figures at $S_{\mathcal{f}}=0.96$, the depth disappears at $m_{g}=6.0$ and at $S_{1}=0.863$ it disappears at 2.5, and at $S_{1}=0$ it disappears at 1.2. Obviously, when $S_{1}=0$, the pinion receives jet impingement only when $m_{g} 1.2$. This 1llustrates the idea that for a given pinion/gear tooth combination we need to know $S_{f}(m i n)$ where no impingement is possible even when the jet velocity $v_{j}$ approaches infinity $\left(v_{j} \rightarrow \infty\right)$. This then allows solutions for $d_{p}$ and $v_{j p}$ when $s_{q}(m i n)<s<1.0$. The gear depths $d_{g}$ area also shown for tooth with a working depth of $0.25 \mathrm{in}$. and therefore primary impingement can only reach about 1/10th the working depth as shown. Figure 8 shows the effect of the inclination angle $B_{1}$ on pinion impingement depth $d_{p}$. As expected when the jet pressure is increased so is the impingement depth and as the $B_{1}$ ratio is decreased the depth is increased up to the maximum depth $d_{p}(\max )$ as a function of $S_{1}$ and $B_{1}$ per Eq. (10).

Figure 9 shows the effect of offset $S_{1}$ on impingement depth $d_{p}$ and $d_{g}$ on a mesh with long and short addendums and a spread center distance 
to accommodate a large gear ratio on a fixed or given center distance. The mesh has been somewhat overcompensated so that $S_{0}$ is negative which is rare and reverses the situation such that the gear now is the member that can be easily starved if the jet nozzle is not placed properly. Here, as can be seen, the depth $d_{g}$ improves as $S_{1}$ is increased above $S_{1}=0.6667$ and when optimized by one of the three methods avallable in IMPOUT2 will still provide an equal impingement depth for both the pinion and gear at dimensionless depth of about $\delta \cong 0.1$, where $\delta=d /$ whole depth. Also usually the program option 3 has a large value than option 2 which is also reversed relative to standard mesh conditions.

Figure 10 shows the results of setting $S_{1}=0$ and $B_{1}=0$ and adjusting the pinion and gear addendums to realize the balance of depths of impingement desired. Here as is seen in Fig. 10, as $\Delta a_{p}$ is reduced $\Delta C$ is reduced and at $\Delta_{p}=0.0662$ an equal (or optimum) impingement depth is reached on the pinion and gear. The connected circles at $A$ depict the depths when $\Delta a_{p}=0.10$ and $\Delta a_{g}=-0.0375$. Obviousiy we must optimize using $S_{1}$ and $B_{1}$ as discussed in Fig. 9. The connected circles at $C$ depicts the depths when $\Delta a_{p}=0.08375$ for the pinion and -0.0375 for the gear are closer together than in "A". Further, when $\Delta a_{p}$ is further reduced to $\Delta a_{p}=0.06875$ as in "B" the depths get much closer together and at $\Delta a_{p}=$ $0.0662=-\Delta a g$ when optimized on $\Delta a$ the depths are equal.

Figure 11 shows the effect of $B_{1}$ on $S_{q}(m i n)$. The 21/35 tooth combination was used as the example here. This figure shows that if $B$ is slanted backwards in the negative direction, that $S_{q}$ can be made smaller before the pintion is starved. Also if the offset $S_{q}$ is set at 1.0 it is nearly impossible to starve the pinion at any reasonable incination angle $B$, or $B_{1}$ ratio, even when the pressure is modest. 
The last Fig. 12 shows the effect of the dimensionless offset $S_{1}$ on the mintmum velocity or its cause, jet nozzle pressure at the nozzle exit $\left(v_{j}(m i n)=\right.$ veloctty needed to reach pinion 0.0.). As is seen in the figure, $S_{f}(m i n)$ establishes the asymptote where $V_{j}(m i n)$ approaches infinity. THis makes it clear that we cannot set $S_{j}$ below $S_{j}(\min )$ and expect to obtain primary impingement on the pinion top land or profile at any jet pressure.

\section{DISCUSSION}

Figures 11 and 12 show the most important results of this study, in that they point out the importance of careful placement of the nozzle in both position and pointing direction, especially at higher gear ratios considered in Fig. 7. Also for out-of-mesh nozzle orientation, increasing the ofl jet pressure and velocity to high levels may not always improve the primary impingement depth appreciably as shown in Figs. 9, 10, and 12, and in practical fact may sometimes cause flooding in the gear case or housing. Further, if the inclination angle $B$ is adjusted to an extreme, per Fig. 8, to improve the Impingement depth on the pinion, then the gear depth is diminished usually unacceptabiy.

Even when the position is fixed in the historically standard orientation position which will not allow primary impingement on the pinion for even modest gear ratios (at any jet pressure), the pinion and gear addendums can be adjusted per Fig. 10 to provide adequate impingement on both mesh members. This has been done in the past to control incipient scuffing or scoring, often without the designer realizing he was also controlling the impingement and cooling phenomena favorably. 
SUMMARY OF RESULTS

An analysis was developed for the lubricant jet flow in the out of mesh condition. THe analysis provides for the inclusion of modified center distances and modifted addendums. The equations are developed for the 1 imit values of variables necessary to remove the severe limitations or constraints necessary to facliltate computer analysis. A computer program was developed using these "Limit Formulas" to prevent negative impingement (missing) on the pinfon. THe following results were obtained:

1. The industrial standard nozzle orientation usually found where the offset $S=0$ and inclination angle $B=0$ will often cause the pinion to be deprived of primary impingement which can be an important cause of incipient gearing fallure in high-speed drives.

2. For ratios larger than $1: 1$, the ofl jet will only impinge on the gear teeth uniess a minimum calculated jet velocity is provided to lubricate the pinion teeth.

3. When a minimum 011 jet velocity is provided, the 011 jet offset must be equal to or greater than a minimum calculated offset to assure impingement on the pinion.

4. As the ofl jet velocity is increased above the calculated minimum value, the impingement depth will increase but at a decreasing rate. The maximum impingement depth will generally not exceed 10 percent of the tooth profile depth. 


\section{REFERENCES}

1. Umezawa, K., Inoh, T. and Katah, H., "Power Loss of Automobile Transmission with Exact Measurement of Total Heat Rejection," The International Symposium on Gearing and Power Transmissions. JSME, Tokyo, Japan, Aug. 30 to Sept. 3, 1981, pp. 287-292.

2. Dudley, D. W., "Characteristics of Regimes of Gear Lubrication," The International Symposium on Gearing and Power Transmissions, JSME, Tokyo, Japan, Aug. 30 to Sept. 3, 1981, pp. 319-324.

3. Naruse, C., Halzuka, S., and Nemoto, R., "Studies on the Limitation Load for Scoring of Gears," The International Symposium on Gearing and Power Transmissions, JSME, Tokyo, Japan, Aug. 30 to Sept. 3, 1981, pp. 371-376.

4. Do1, Y., et al., "On Bulk Temperature in High Speed and Heavy Duty Gears," The International Symposium on Gearing and Power Transmissions, JSME, Tokyo, Japan, Aug. 30 to Sept. 3, 1983, pp. 247-252.

5. Akin, L., Mross, J. J., and Townsend, D. P., "Study of Lubricant Jet Flow Phenomena in Spur Gears," Journal of Lubrication Technology, Vol. 97. Ser. F, No. 2, Apr. 1975, Pp. 283-288.

6. Townsend, D., and Akin, L., "Analytical and Experimental Spur Gear Tooth Temperature as Affected by Operating Vartables," 1980, Journal of Mechanical Design, Vo1. 103, No. 4., Jan. 1981, pp. 219-226.

7. Akin, L. S., and Townsend, D. P., "Into Mesh Lubrication of Spur Gears with Arbitrary Offset, Part I - For 011 Jet Velocity Less Than or Equal To Gear Velocity," Journal of Mechanisms, Transmissions and Automation in Design, Vol. 105, No. 4., Dec. 1983, pp. 713-718. 
8. Akin, L. S., and Townsend, D. P., "Into Mesh Lubrication of Spur Gears with Arbitrary offset, Part II - For 011 Jet Velocity Equal To or Greater Than Gear Velocity," Journal of Mechanisms, Transmissions and Automation In Design, Vol. 105, No. 4., Dec. 1983, pp. 719-724.

9. Townsend, 0., and Akin, L., "Study of Lubricant Jet Flow Phenomena in Spur Gears - Out of Mesh Condition," Journal of Mechanical Design. Vol. 100, No. 1., Jan. 1978, pp. 61-68. 


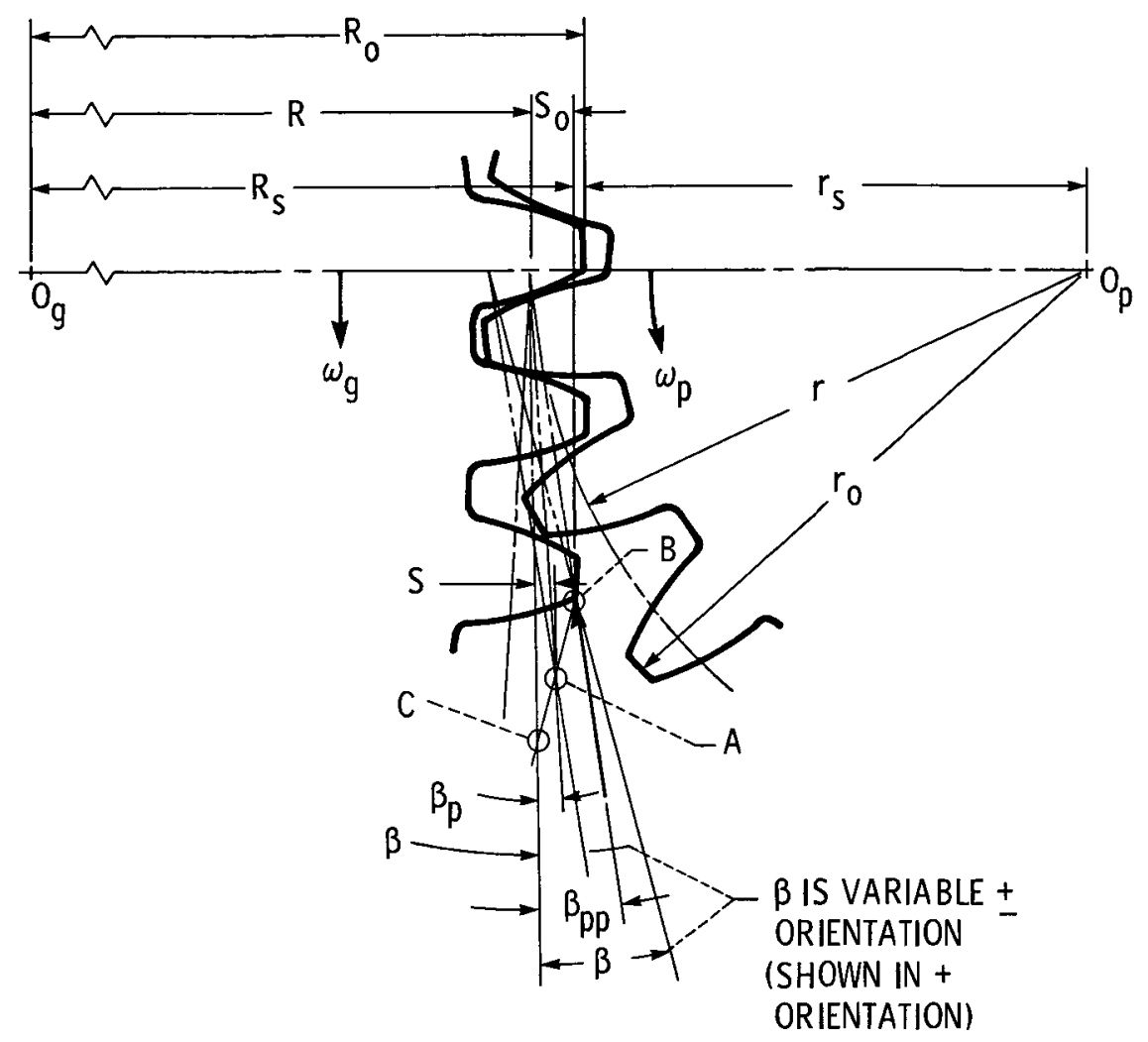

Figure 1. - Jet coordinate origins for impingement on pinion. $A=$ general case where $0<\mathrm{S}<\mathrm{S}_{0} ; \mathrm{B}=$ special case where $\mathrm{S}=\mathrm{S}_{0} ; \mathrm{C}=$ classic case where $\mathrm{S}=0^{\circ}$.

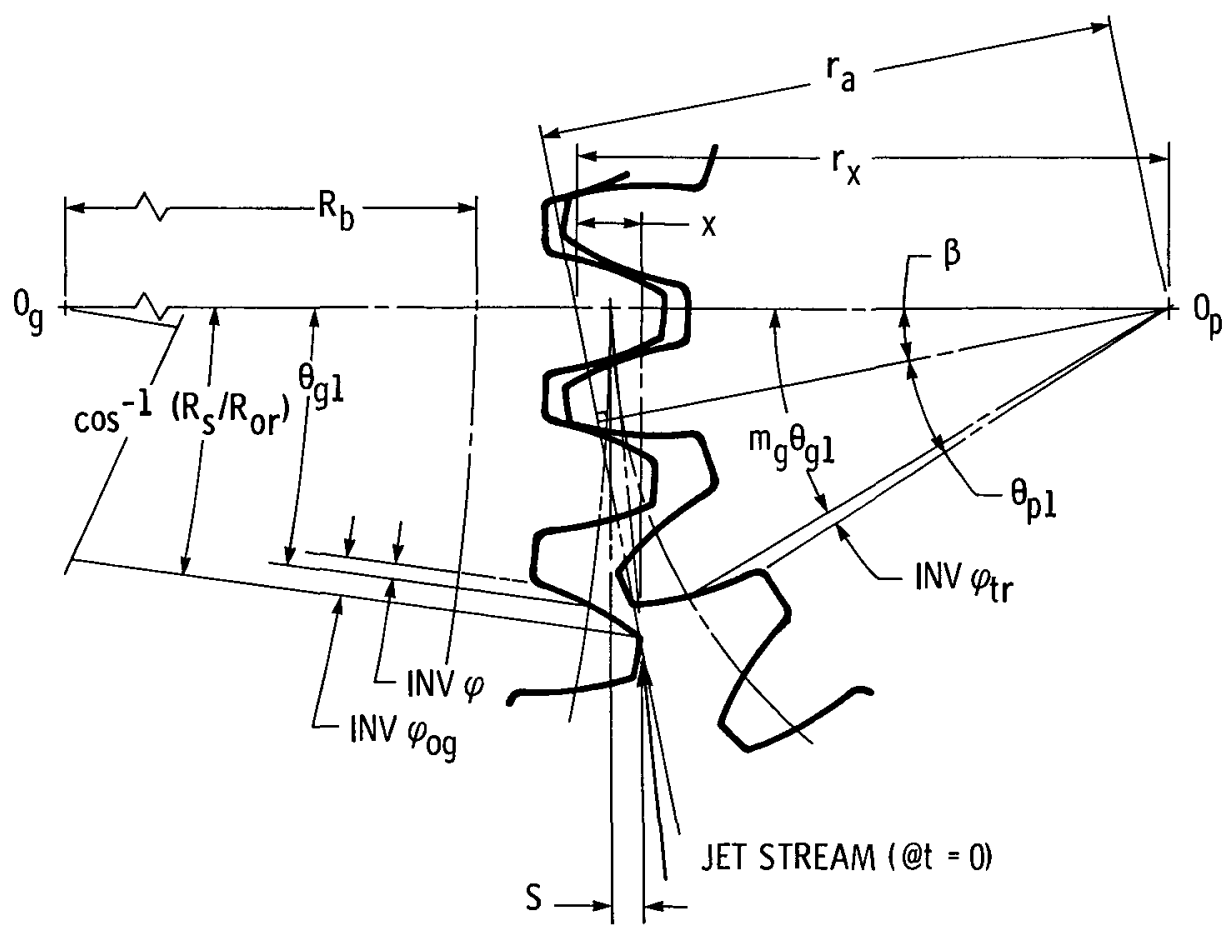

Figure 2. - Impingement on pinion (@t = 0). 


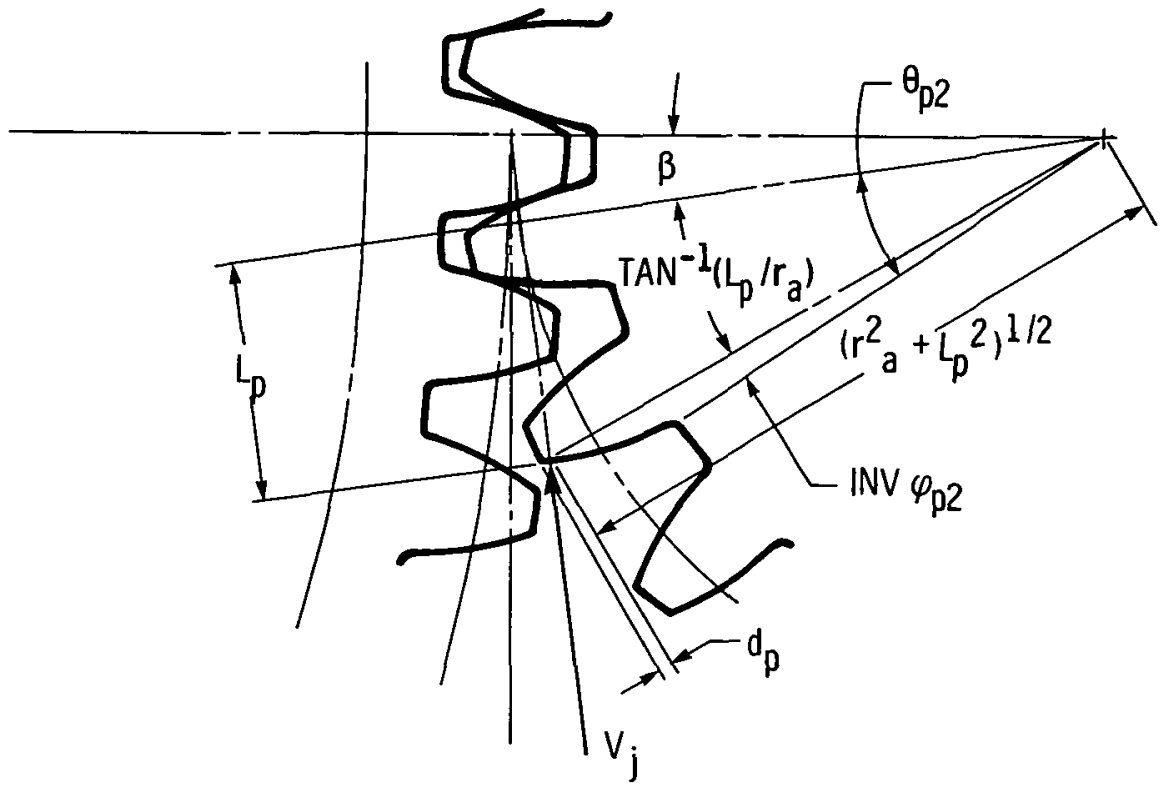

Figure 3. - Impingement on pinion (@t $\left.t_{f}=t_{\omega}\right)$.

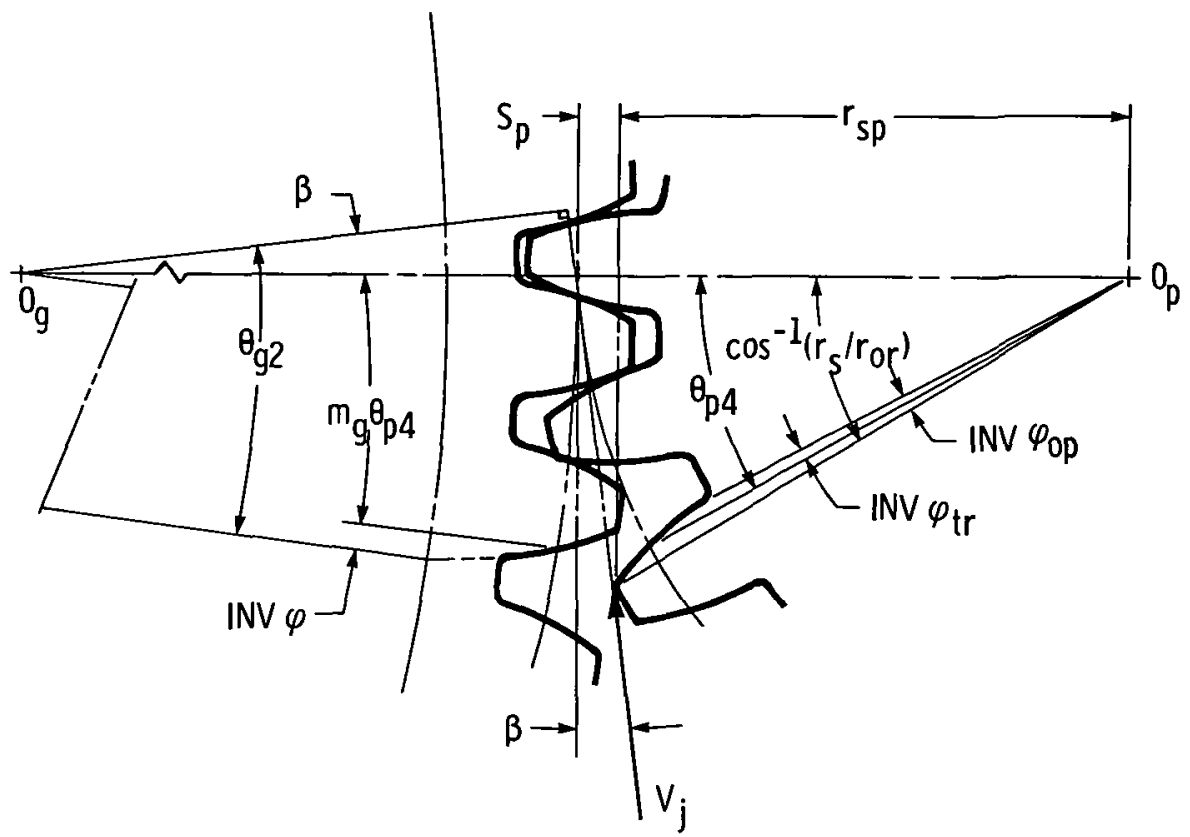

Figure 4. - Impingement on gear $(@ t=0)$. 


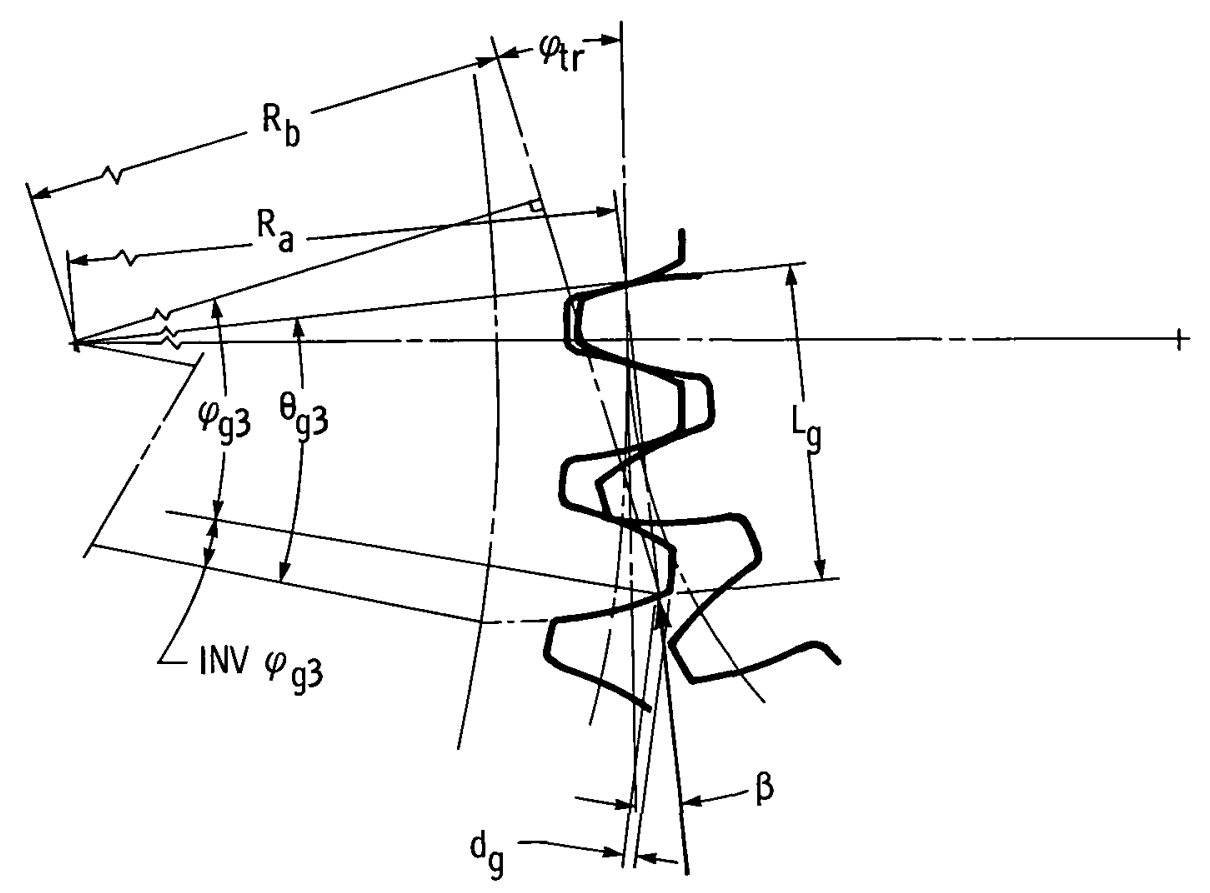

Figure 5. - Impingement on gear $\left(@ t_{f}=t_{\omega}\right)$.

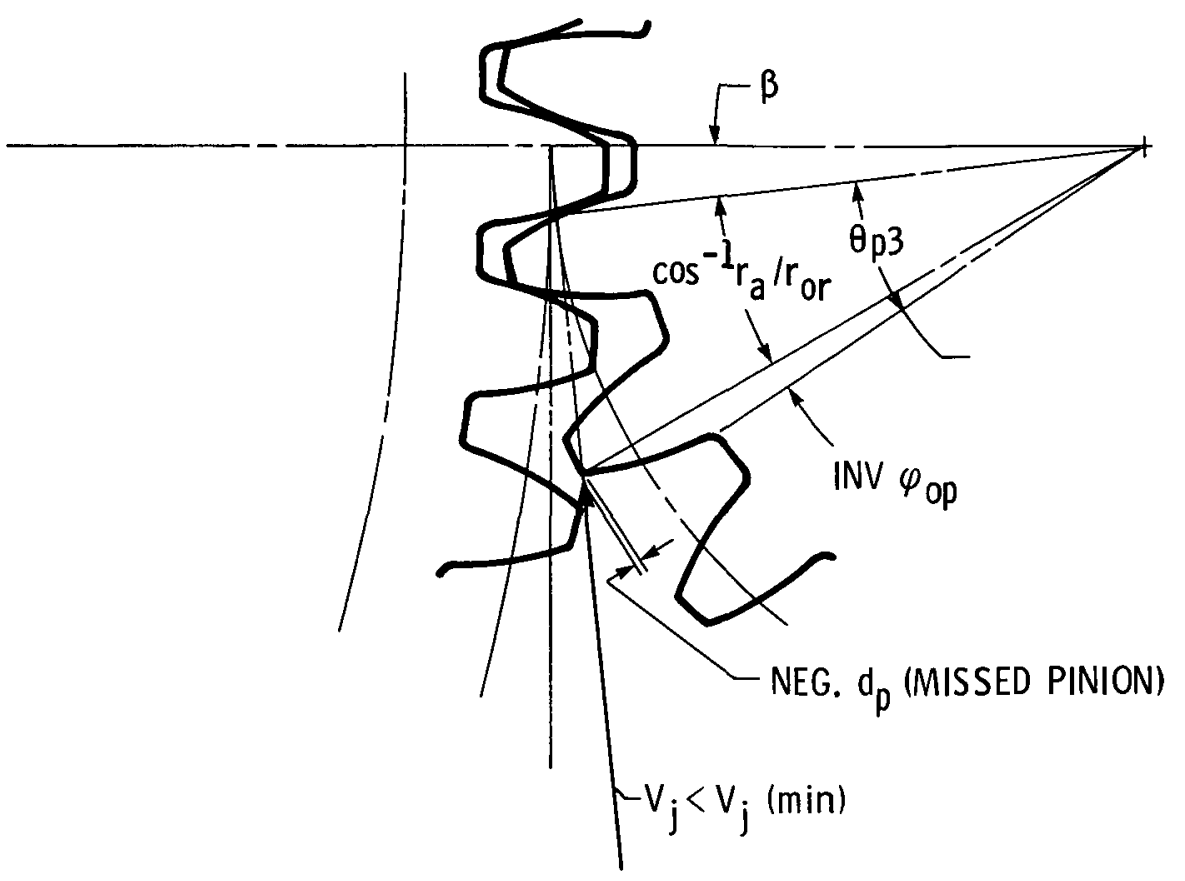

Figure 6. - Missing the pinion when $v_{j}<v_{j}$ (min). 




Figure 7. - Effect of gear ratio on impingement depth, $\beta_{i}=0$, $\Delta P=138 \mathrm{psi}, \mathrm{n}=5000 \mathrm{rpm}, \mathrm{N}_{\mathrm{p}}=28$.

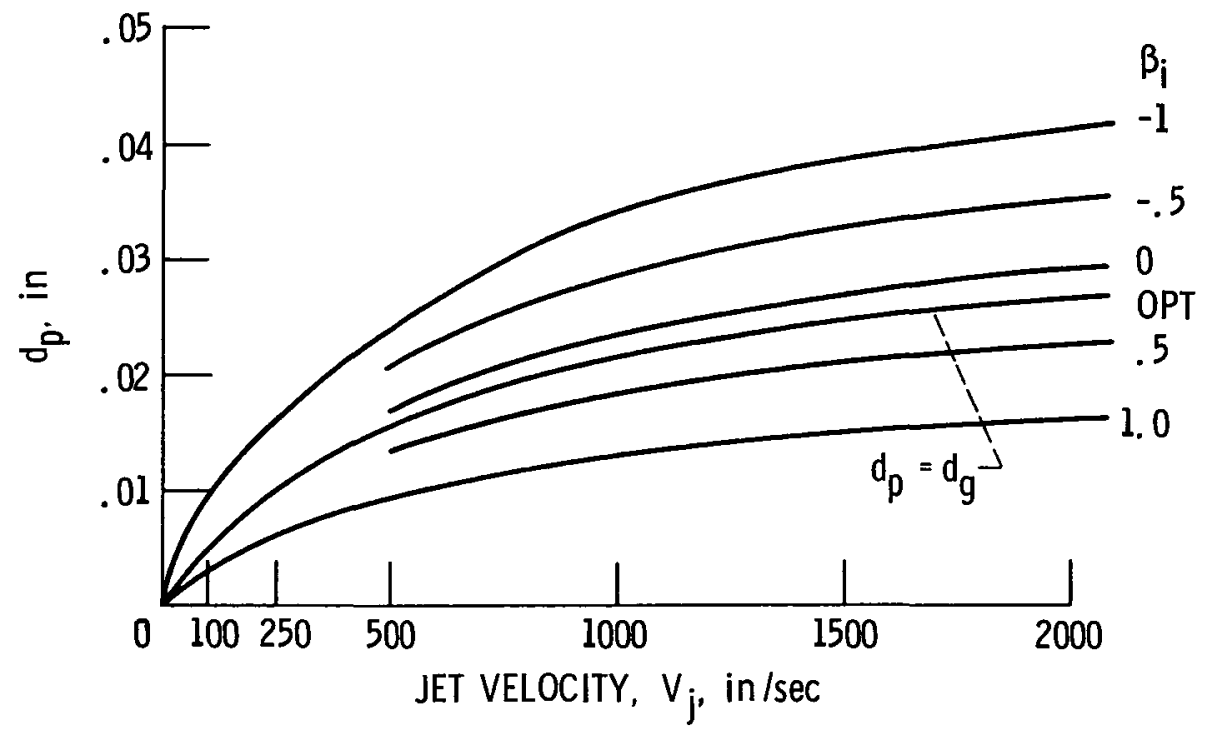

Figure 8. - Effect of $\beta_{i}$ on impingement depth, $S_{i}=1.0$, 21/35 combination. 




Figure 9. - Effect of offset $S_{j}$ on impingement depth. $12 / 43$ comb. $, \beta_{\mathrm{i}}=0, \Delta \mathrm{a}_{\mathrm{g}}=-.0375 . \Delta \mathrm{c}=.0625, \Delta \mathrm{a}_{\mathrm{p}}=.1, \mathrm{DP}=$ $8, \varphi=200$.
$1 \mathrm{~d}_{\mathrm{p}}, \Delta \mathrm{a}_{\mathrm{p}}=.10, \Delta \mathrm{a}_{\mathrm{g}}=-.0375, \Delta \mathrm{c}=.0625$

$\mathrm{d}_{\mathrm{p}}, \Delta \mathrm{a}_{\mathrm{p}}=.084375, \Delta \mathrm{a}_{\mathrm{g}}=-.0375, \Delta \mathrm{c}=.046875$

$3 \mathrm{~d}_{\mathrm{g}}, \Delta \mathrm{a}_{\mathrm{p}}=.06875, \Delta \mathrm{a}_{\mathrm{n}}=-.0375$

$4 \mathrm{~d}_{\mathrm{p}}=\mathrm{d}_{\mathrm{g}}, \Delta \mathrm{a}_{\mathrm{p}}=-\Delta \mathrm{a}_{\mathrm{g}}=.0662$, OPTIMIZED

$5 \mathrm{~d}_{\mathrm{g}}, \Delta \mathrm{a}_{\mathrm{p}}=.084375, \Delta \mathrm{a}_{\mathrm{g}}=-.0375$

$6 \mathrm{~d}_{\mathrm{p}}, \Delta \mathrm{a}_{\mathrm{p}}=.06875, \Delta \mathrm{a}_{\mathrm{g}}=-.0375, \Delta \mathrm{c}=.03125$

$7 \mathrm{~d}_{\mathrm{g}}, \Delta \mathrm{a}_{\mathrm{p}}=.10, \Delta \mathrm{a}_{\mathrm{g}}=-.0375$

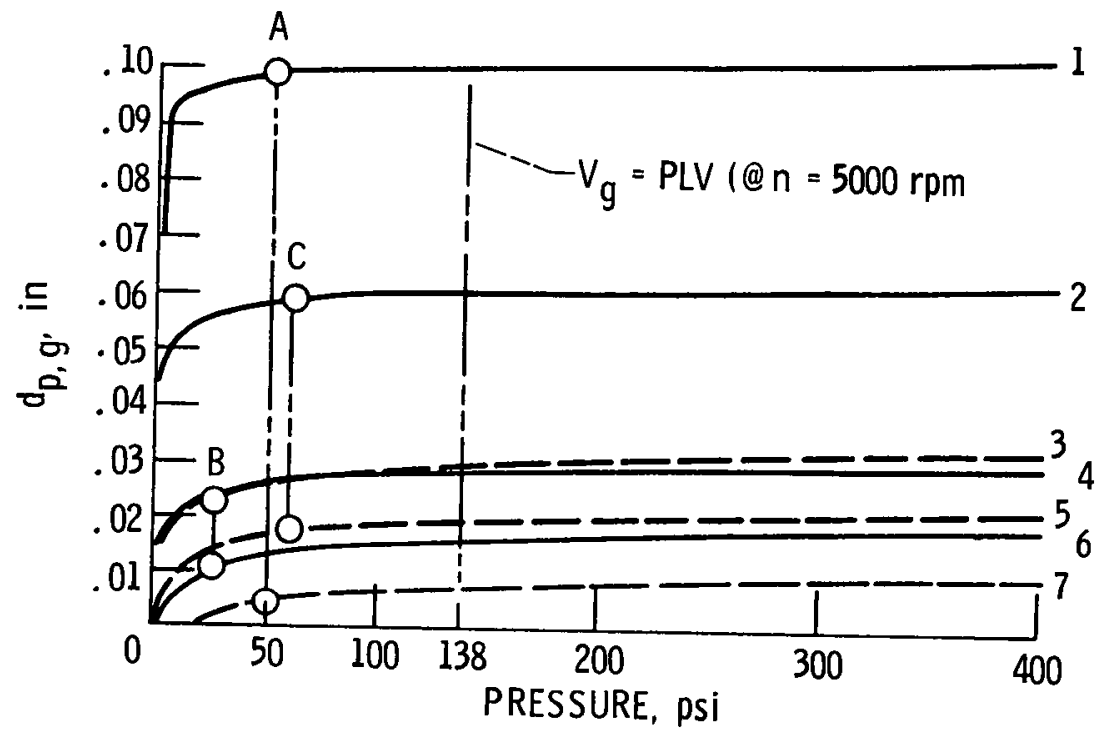

Figure 10. - Effect of addendum modification and spread centers. $S_{i}=0, \beta_{i}=0$, for $12 / 43$ tooth combination. 




Figure 11. - Effect of $\beta_{i}$ on $S_{i}$ (min), 21/35 combination, $\varphi=$ $20, P_{d}=8$.

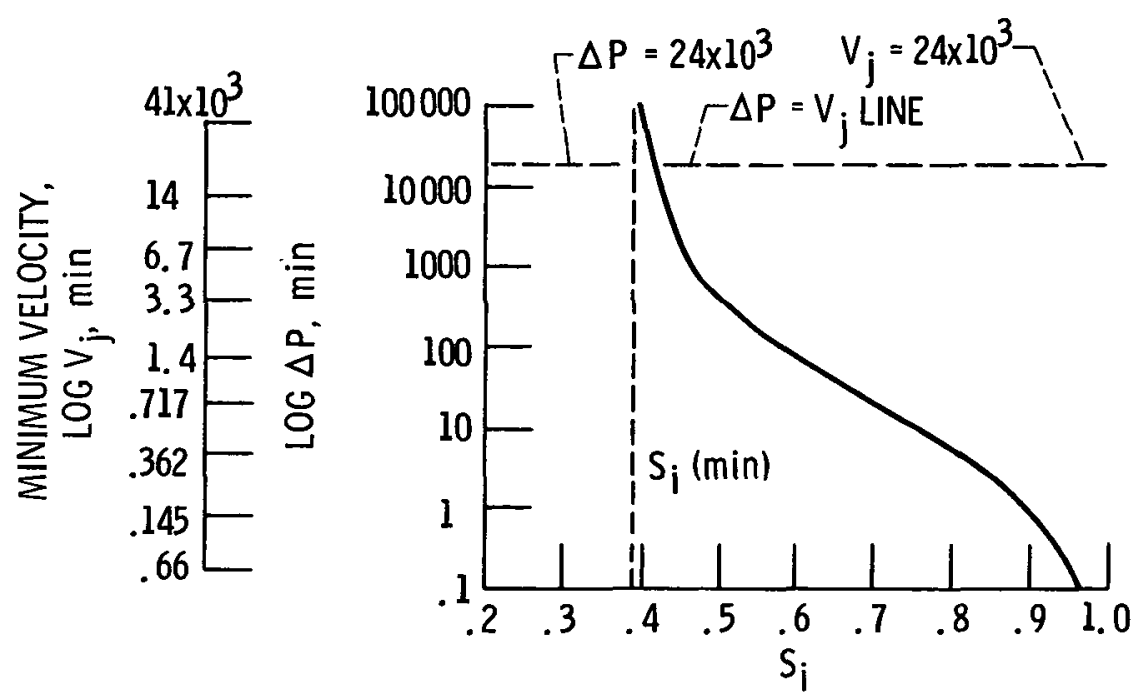

Figure 12. - Minimum differential oil pressure " $\Delta P(\min ) "$ versus dimensionless offset " $S_{i}$ ", 21/35 combination, $8 D P, 20^{\circ} \mathrm{PA}, \beta_{\mathrm{i}}=0, V_{\mathrm{j}}=156 \sqrt{\Delta \mathrm{P}}, 5000 \mathrm{rpm}$. 




-For sale by the National Technical Information Service, Springfield. Virginia 22161 
National Aeronautics and Space Administration

SPECIAL FouRtM Class MAIL BOOK

Washington, D.C.

20546

Official Business

Penatty for Private Use, $\mathbf{5 3 0 0}$

Potroe and Fees Pand

Netional Aeronoutics and

Spece Administration

NASA 451 